\title{
Indigenous Weather Forecasting Systems: A Case Study of the Abiotic Weather Forecasting Indicators for Wards 12 and 13 in Mberengwa District Zimbabwe
}

\author{
Kampion Shoko ${ }^{1} \&$ Nothabo Shoko ${ }^{2}$ \\ ${ }^{1}$ Department of Geography and Environmental Studies, Midlands State University, Gweru, Zimbabwe \\ ${ }^{2}$ Department of Educational Foundations, Management and Curriculum Studies, Midlands State University, \\ Gweru, Zimbabwe \\ Correspondence: Kampion Shoko, Department of Geography and Environmental Studies, Midlands State \\ University, Private Bag 9055, Gweru, Zimbabwe. Tel: 263-773-642 624. E-mail: kampion0054@gmail.com
}

\author{
Received: February 17, 2013 Accepted: March 22, 2013 Online Published: April 27, 2013 \\ doi:10.5539/ass.v9n5p285 URL: http://dx.doi.org/10.5539/ass.v9n5p285
}

\begin{abstract}
Residents of wards 12 and 13 in Mberengwa depend on agriculture as a source of livelihood. They have since developed their own indigenous weather forecasting systems which they have been using in conjunction with meteorological weather forecasts in the planning and execution of their agricultural activities. These systems are used singularly or are complimented with the conventional meteorological forecast from the Meteorological Services Department. The main objective of this research was to identify the abiotic weather forecasting indicators as well as to acquire information on how they are used. Questionnaires, focus group discussions and interviews with key informants were used to collect the data. Key informants were those whose time of residence in the wards was more than 50 years.

Investigations revealed that the residents rely mostly on environmental indicators for planning agricultural activities. Results showed that of the two categories of indigenous abiotic weather forecasting indicators, weather forecasts derived from weather indicators were the mostly used followed by forecasts derived from celestial indicators. There were however differences on the interpretations of the behavioural signs or indicators which were used in the production of the forecasts from these abiotic factors.

The study recommends that further research should be carried out on the application and on the statistical evaluation of the precision of the indigenous forecasts. Attempts should also be made to document the abiotic weather indicators and the behavioural signs from which these forecasts are derived. The establishment of an effective indigenous weather forecasting system as part of a decision support system would go a long way in improving food security for this area
\end{abstract}

Keywords: indigenous weather forecasting, celestial body indicator, weather indicator, behavioural sign, environmental indicator, drought

\section{Introduction}

Weather forecasts are an essential input to agricultural production. The forecasts can be processed and disseminated from the Meteorological department which at times is not accessible to most of the rural people. These people rely on weather forecasting indicators derived from their environment to make strategic decisions in their day to day lives especially in agriculture.

Zimbabwe's economy is agro-based, contributing about $70 \%$ of the country's revenue (Ministry of ForeignAffairs Zimbabwe, 2011). Since agriculture is heavily dependent on weather and in particular rainfall and temperature, in areas where rainfall is erratic and inadequate, agricultural productivity becomes highly correlated to weather. Wards 12 and 13 in Mberengwa are in agro-ecological region 4 where rainfall is unreliable and inadequate. Strategic decision making and planning such as when to plant and which crops to grow for a particular year are all effectively done using weather information derived from indigenous forecasts and to a lesser extent, conventional meteorological forecasts. Livestock numbers, water resources and pasture management all depend on weather forecasts and in particular, rainfall forecasts. 
Most of the residents of Wards 12 and 13 do not access seasonal and daily weather forecasts from the Meteorological department. Where Meteorological forecasts are received through the radio, lack of skill in interpretation and application of these forecasts becomes a hurdle as this requires Meteorological and Agricultural extension officers. These people need simple and easy to apply agro- meteorological products which are not readily available. Hence these residents are then left with no choice but to use their indigenous knowledge to make weather predictions.

\subsection{The Role of Indigenous Knowledge Systems (Iks) and Early Warning Sytems (Ews)}

To effectively utilize land and make precise agricultural management decisions appropriate $E w$ s depending on rainfall, agriculture and market data are essential. Therefore efforts must also be made to build on farmers' Iks, Mararike (1999) discusses the use of $I k s$ in predicting rain or drought seasons. The people try to make meaning out of the environment in which they live. This knowledge is key to any planning process at the lowest level and enables agencies to act in a timely way. The question is "Has this knowledge been effectively identified and utilized in various areas?" According to studies carried out by UNEP (2002), the Hausa of Northern Nigeria, for example, developed a wealth of Iks to cope with vulnerability to drought and famine in sub-humid to arid regions of the Sahel. These included inter-cropping with nitrogen fixing legumes, intensive manure application, soil conservation works, poly-cultural production of different cereals to cope with variable soil moisture regimes and exploiting different ecological needs to support wet and dry season production respectively. Studies carried out by Mararike (1999) in Buhera reveal that there are a lot of indicators for rain or drought seasons for example the singing of a bird called 'haya' in the early summer is believed to herald the start of rainy season. These Iks are fast disappearing in Wards 12 and 13 of Mberengwa district and it is time to rediscover lost knowledge and document it, as it is vital to Africa's development and in coping with drought. A study carried out by Nyong, Adesina and Elash (2007) in the African Sahel on the value of indigenous knowledge in climate change mitigation revealed that indigenous knowledge had been utilised as an adaptation strategy in this region in climate change mitigation. Adaptation strategies included assessment of vulnerability and implementation of appropriate adaptation strategies for climate change.

Shoko (2012) also studied the biotic weather forecasting indicators for wards 12 and 13 in Mberengwa. The results of the study revealed that the residents of these wards rely heavily on the rain cuckoo and the ground hornbill to make daily weather predictions and seasonal rainfall forecasts. A related study by Risiro, Mashoko, Tshuma and Rurinda (2012) on weather forecasting and indigenous knowledge systems in Chimanimani district of Manicaland in Zimbabwe also revealed that the residents of this district utilize both the biotic and abiotic indicators in decision making. The abiotic weather indicators used in this district are atmospheric weather forecasting indicators that include changes in weather elements such as temperature, wind and rainfall. Astronomical indicators used by the residents are, the stars (Milky Way), moon phases and the rainbow.

Makwara (2013) argues that when indigenous knowledge gets adopted for widespread use, it becomes common as traditional knowledge and it becomes subject to change or improvement by the users without any control or reference to the original source. Therefore, indigenous knowledge systems are dynamic and can be improved with time according to the influence of the outside world. This argument emphasizes the need to carry out continual research on indigenous knowledge.

\subsection{The History of Indigenous Weather Forecasting}

Out of all the various factors which control agricultural production, weather is the only factor over which man has no control and hence it has overwhelming dominance over the success or failure of an agricultural enterprise. Weather induced variability of food production ranges from $10 \%$ to $50 \%$ in arid and semi arid regions. In order to reduce risks of loss in food production due to the vagaries of weather, weather forecasts should be taken into account in all agricultural planning. Thus the development of weather prediction systems and expert indigenous weather systems is important and has been a necessity since time immemorial. In the absence of improved technologies for weather forecasting, farmers could derive their prediction from natural, cultural and even social phenomena. Some of these are:

(a) Visible spectrum around the sun and moon (halo). The size of the halo determines the amount of rainfall, large implies lots of rainfall while small implies scanty rainfall.

(b) Cloud and wind direction. The predictions from weather related indicators such as wind direction and cloud cover vary with location.

Weather prediction can also be made from closely observing biotic factors such as birds, vegetation and animals (http://www.telegraph.co.uk/earth/earthnews/3301595/Australia-taps-Aboriginal-weather-knowledge.html). 
The website goes on to give examples of the following as weather prediction from biotic factors.A bird indicator is the lapwing bird (Tatihari) found in Australia. When it lays its eggs on the upper part of the field then good rains are expected and poor or no rains when it lays eggs on the lower part of the field. It is further believed that if it one egg then rains will fall for one month and two eggs imply that rains will fall for two months. The rainfall season lasts for four months in this region (Australia).

An example of an animal indicator is the camel. When there is a swelling on the lower parts of the camel's legs, rainfall is expected any time. Creatures such as centipedes and spider nests just to name a few are also used.

Social and cultural beliefs and rain making ceremonies are part of many societies.In the northern parts of India environmental weather predictors such strong easterly winds mean the rain season has come. When a rainbow is formed in the direction of Bengal, it implies that rain might fall by evening then if not definitely it will fall by the next morning. During the rainy season if cloud appears on Friday or Saturday, then rainfall is predicted for either Sunday or Monday.

According to the same website aboriginal society has a philosophy that all things are connected and that subtle natural linkages are present which can reveal much about the climate and weather. So they derive their weather forecasts from environmental indicators. These indigenous weather forecast are now being incorporated into the conventional weather forecasts from the Australian weather Bureau particularly in the tropical north. The aboriginal indigenous forecasts have a high precision.

The chaotic nature of the dynamics of the atmospheric system has always posed a problem in weather forecasting. This has affected the precision of weather forecasts not only in Zimbabwe but worldwide. The situation is worse for indigenous weather forecasts which are subjective in nature and their precision depends on a variety of factors such as the age of the respondent, level of education and period of residence in the area just to mention a few In most cases both conventional and indigenous weather forecasts are not even available. Where these forecasts are available capturing the benefits of these forecasts is hampered by lack of skills in the interpretation and application of these forecasts (Shoko \& Shoko, 2011). People in rural or remote areas rely mostly on indigenous weather forecasting systems to get daily and seasonal weather forecasts. These indicators are derived from the environment and differ from place to place. The study will help identify the indigenous weather forecasting systems in this area and assess their precision. The results can be used in improving the accuracy of weather forecasts and to make adept agricultural strategic decisions not only in this area but in other areas with a similar environment in Zimbabwe and worldwide.

\subsection{Statement of the Problem}

Meteorological forecasts are highly technical in nature, such that most people can not understand them hence they derive minimal or no benefits from such forecast. Besides, these forecasts are available at a cost which the rural people can not afford. This leaves them vulnerable to all the vagaries of weather that may lead to poor yields and food insecurity. So the thrust of this research was to find indigenous forecasting solutions to the problem cited above by tapping indigenous forecasting knowledge, which is less technical in nature and inexpensive to the user.

\section{$1.4 \mathrm{Aim}$}

The aim of this research was to investigate the indigenous weather forecasting systems being employed in Wards 12 and 13 of Mberengwa district.

\subsection{Objectives}

The objectives of this research were to:

1) assess the level of accessibility of the conventional Meteorological daily weather forecasts and seasonal forecasts in the two wards.

2) identify the abiotic indicators used in indigenous weather forecasting systems in Wards 12.and 13

3) document the behavioural signs and their interpretations for the various abiotic environmental indicators.

4) rank the abiotic indicator categories.

\subsection{Justification for the Study}

Wards 12 and 13 depend on agriculture for food and as a means of acquiring finances to sustain economic needs. On the other hand, the area has erratic and unreliable rainfall making it one of the most drought prone areas of Zimbabwe. The area receives precipitation amounts ranging from 300 to $500 \mathrm{~mm}$ per year. The rainy season stretches from late November to March. An agro-based livelihood system like that of Wards 12 and 13 requires 
adept planning by the inhabitants. Timely planting, selection of the appropriate crop cultivars, as well as practicing an animal husbandry system suitable to the local climate are imperative.

Decision making is based on anticipated rainfall and to a lesser extent on the availability of agricultural inputs. Weather forecasts and in particular seasonal rainfall forecasts have limited accessibility. This leaves most of the farmers with no option but to rely on forecasts derived from indigenous indicators. Where the Meteorological forecasts are accessed, limited understanding of the forecasts and poor skills in making appropriate agro-meteorological decisions become a hurdle. As a result, most of the residents are left with no option but to use their indigenous knowledge based on biotic and abiotic components of their environment, which they understand better.

Identifying the indigenous weather forecasting indicators and acquiring information on how they are used will not only improve food production in this area, but will also be useful to other people, living under similar environmental conditions elsewhere. It is also anticipated that knowledge on the interpretation of the behaviours or symptoms from the environmental indicators will be documented, so that the indigenous weather forecasting system can be improved. The behaviours or signs that are similar should have the same weather forecast inferred from them for a particular area, so it is hoped that the findings from this research will help bring this much needed alignment and thus solve the existing problem where a multitude of differing forecasts are derived from the same indicators and behaviours. This should add value to the indigenous forecasting system and also improve its precision. It is anticipated that this research will encourage scholars and readers to undertake similar research on abiotic weather forecasting indicators.

Finally, the indigenous weather forecasting system should be blended with the Meteorological forecasts to produce a more accurate and user-friendly indigenous weather forecasting system. This view is supported by Risiro etal, 2012 and Shoko, 2012. It is also hoped that knowledge will be imparted to all the residents on how to use the indigenous weather forecasting system for their benefit.

\subsection{Area of Study}

Mberengwa is a district in Zimbabwe situated $180 \mathrm{~km}$ south of Gweru and 24km southwest of Zvishavane and most of the district apart from the study area which is in Natural Farming Region V, falls in Natural Farming Region IV. The majority of the people in this area depend wholly on farming for their survival. Farming in this area is however affected by rainfall variability. Rainfall in this area ranges from $300-500 \mathrm{~mm}$ per year and the length of the growing season is only about 111 days. Droughts are very common in this area and it has been noted that there are usually 4 moderately dry years in 5 years, which means there is only one good season in 5 years. Mid-season droughts are also very common. Intra-season dry spells occur without fail even in good years and the average is about 10-20 days mainly in January. The study was carried out in Mberengwa West where wards 12 and 13 are situated. The wards comprise six villages and the population is about 5987 (CSO, 1992). There are 948 households in the ward. 


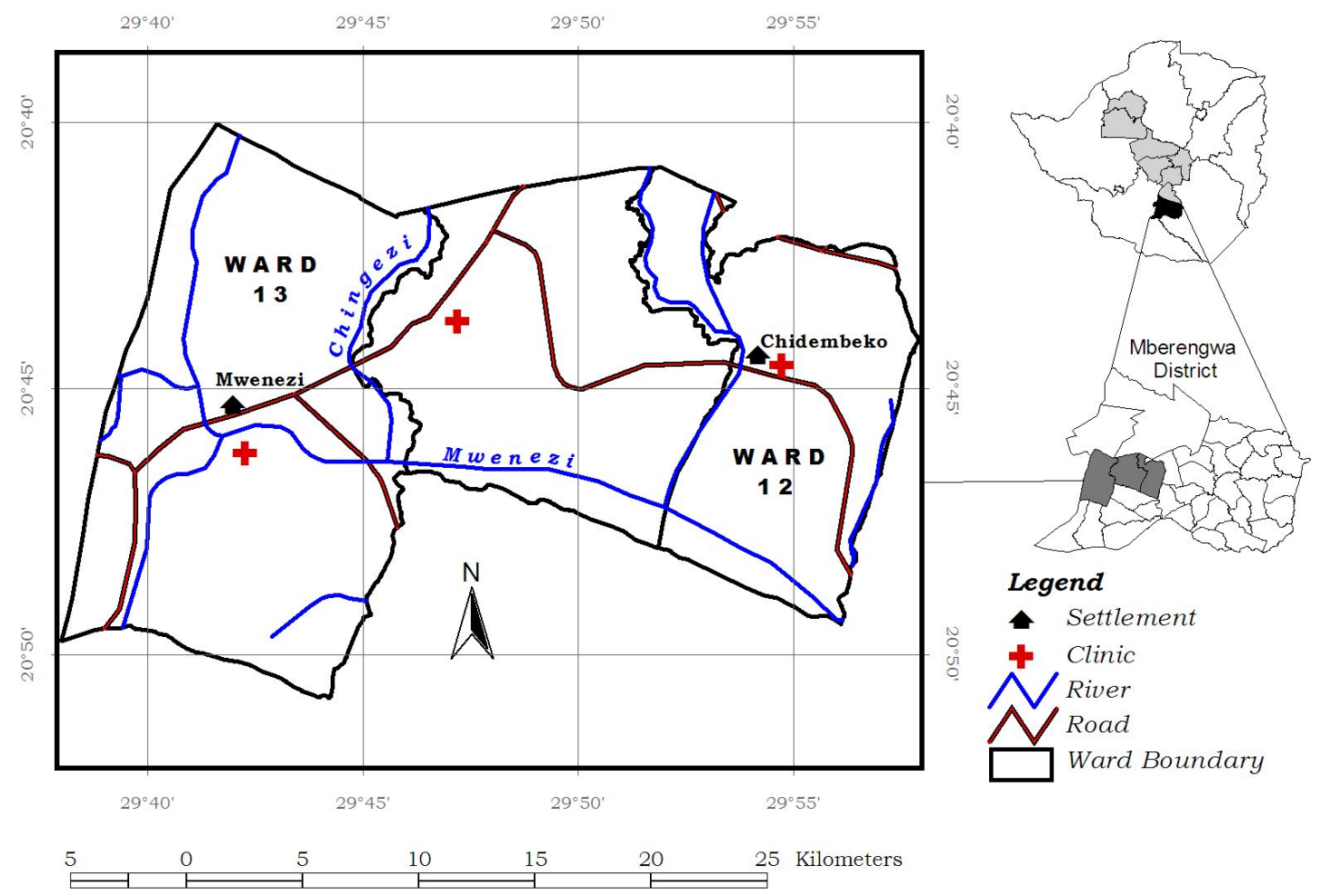

Figure 1. Map of the study area

\subsection{Definition of Terms}

Early Warning Systems(Ews) -refers to a range of systems for data collection, analysis and communication. This range goes from elementary, community based systems of observation and communication to highly sophisticated systems involving satellite observation and communication computer simulation and scores of specialists.

Drought -periods of increased dryness due to precipitation falling far short of expected of that expected for a region. Meteorologists define drought solely on the basis of the degree of dryness and the duration of the dry period whilst agriculturalists link drought to agricultural impacts focusing on precipitation shortages.

Indigenous knowledge systems(Iks) -refers to knowledge of the local environment and how people try to put the world around them in some kind of order, some kind of system which is intended to assist in making decisions on appropriate ways of planning survival strategies

Indigenous weather forecast - This is a weather forecast derived from environmental biotic and a biotic indicators. The behaviour of living organisms are interpreted to tell future weather events as well as other states of both biotic and abiotic environment.

Weather indicator: - Weather phenomenon or prevailing weather conditions from which a weather forecast can be made

Celestial body indicator: -This is a heavenly body namely sun, moon and the stars from which forecasts are derived

Guti weather- In Zimbabwe, a dense stratocumulus overcast, frequently with drizzle, occurring mainly in early summer, and associated with easterly winds that invade the interior, bringing in cool and stable maritime air when an anticyclone moves eastward south of Africa http://www.answers.com/topic/guti-weather

\section{Methods and Materials}

The collection of data was done through questionnaires and focus group discussions. A total of 79 questionnaires 
were administered, 45 in ward 12 and 34 in ward 13. One focus group discussion was conducted per ward to compliment information gathered from questionnaires. The questionnaires were administered to selected persons aged 20 and above. Interviews were carried out with key informants above 50 years. The minimum age limit of 20 years ensured that only respondents with good indigenous knowledge of the area were interviewed. This helped to ensure both validity and reliability of the data collected.

\subsection{Questionnaire}

The questionnaire sought to elicit information on the following aspects:

1) Identification of the abiotic indigenous weather forecasting systems used in the two wards

2) Documentation of the abiotic indigenous weather forecasting indicators and their interpretations

3) Accessibility of the meteorological weather forecasts to the residence of the two wards.

4) Recommendations to improve the indigenous weather forecasts.

\subsection{Focus Group Discussions}

Focus group discussions were carried out after the questionnaires. One focus group discussion was conducted in each of the two wards. These discussions were aimed at establishing consensus on which indicators were most popularly used, the ranking of the indicators and to enlist suggestions on the best possible ways of improving the indigenous forecasts derived from the a-biotic environment.

\subsection{Interviews with Selected Key Persons}

These interviews were carried out after the administration of the questionnaires and the focus group discussions and were restricted to persons over 50 years. This ensured the acquisition of authentic information since these persons had resided for long periods in this particular environment. Four and two people were interviewed in wards 12 and 13 respectively. During these discussions, all the indicators and particularly the state or the signs for abiotic indicators were discussed and documented.

\subsection{Analysis Procedures}

Information on how the forecasts are derived from the indicators was documented. The indicator or the behavioral signs were noted as well as the corresponding forecast from the indicator. The abiotic weather indicators for the study were divided into categories as follows:

1) Weather related indicators

2) Celestial body indicators

Information from questionnaires was analysed and inferences were made from graphs, pie charts and tables derived from the responses. The most used indicators were identified and matched with the corresponding signs or state of the indictor. Ranking of the indicators in terms of use per category was also done.

\section{Results and Discussions}

\subsection{Analysis of Data from Questionnaires}

The data from questionnaires was analyzed and the results are presented below beginning with demographic characteristics of the sample.

Table 1. Distribution of respondents according to age group and gender

\begin{tabular}{lllll}
\hline $\mathrm{N}=79$ & Ward 12 & & Ward 13 & \\
& $\mathrm{n}=26$ & $\mathrm{n}=19$ & $\mathrm{n}=25$ & $\mathrm{n}=9$ \\
\hline Age Group & Male & Female & Male & Female \\
$20-30$ & $11.5 \%$ & $5.2 \%$ & $12 \%$ & $22 \%$ \\
$31-40$ & $15.3 \%$ & $10.5 \%$ & $20 \%$ & $22 \%$ \\
$41-50$ & $15.3 \%$ & $10.5 \%$ & $24 \%$ & 33 \\
$51-60$ & $11.5 \%$ & $52.6 \%$ & $24 \%$ & $0 \%$ \\
$61-70$ & $23.07 \%$ & $10.5 \%$ & $8 \%$ & $0 \%$ \\
$71-80$ & $7.6 \%$ & $5.2 \%$ & $8 \%$ & $11 \%$ \\
Over 80 & $15.3 \%$ & $5.2 \%$ & $4 \%$ & $11 \%$ \\
\hline
\end{tabular}


Table 2. Period of residence of respondents according to gender $\mathrm{N}=79$

\begin{tabular}{|c|c|c|c|c|}
\hline \multirow[t]{3}{*}{ Period of residence } & \multicolumn{2}{|c|}{ Ward 12} & \multicolumn{2}{|c|}{ Ward 13} \\
\hline & $\mathrm{n}=26$ & $\mathrm{n}=19$ & $\mathrm{n}=25$ & $\mathrm{n}=9$ \\
\hline & Male & Female & Male & Female \\
\hline 20-30 years & $15.3 \%$ & $21 \%$ & $8 \%$ & $22 \%$ \\
\hline 31-40years & $11.5 \%$ & $15.7 \%$ & $20 \%$ & $22 \%$ \\
\hline 41-50years & $11.5 \%$ & $21 \%$ & $12 \%$ & $33 \%$ \\
\hline 51-60years & $34.6 \%$ & $26.3 \%$ & $40 \%$ & $0 \%$ \\
\hline 61-70years & $7.6 \%$ & $10.5 \%$ & $8 \%$ & $0 \%$ \\
\hline $71-80$ years & $7.6 \%$ & $0 \%$ & $8 \%$ & $11 \%$ \\
\hline Over 80 years & $11.5 \%$ & $5.2 \%$ & $4 \%$ & $11 \%$ \\
\hline
\end{tabular}

Table 2 shows the number of people who have resided in the ward for a given period. For example $15.3 \%$ males have resided in ward 12 for over 80 years and 52.6\% females of the same ward have been resident for $51-60$ years. This could mean that most of the respondents had a good knowledge of the local environment and had the opportunity to use environmental weather forecasting indicators in their weather sensitive planning decisions. For both wards, $50.6 \%$ respondents have been resident in the area for 51 years and above. This implies that the information they gave was reliable and authentic. Long period of residence in the wards enables one to acquire knowledge on environmental indicators and how they are used to predict the weather. Males and females who participated are shown against their corresponding age groups.

\subsection{Means of Livelihood for the Residents of Wards 12 and 13.}

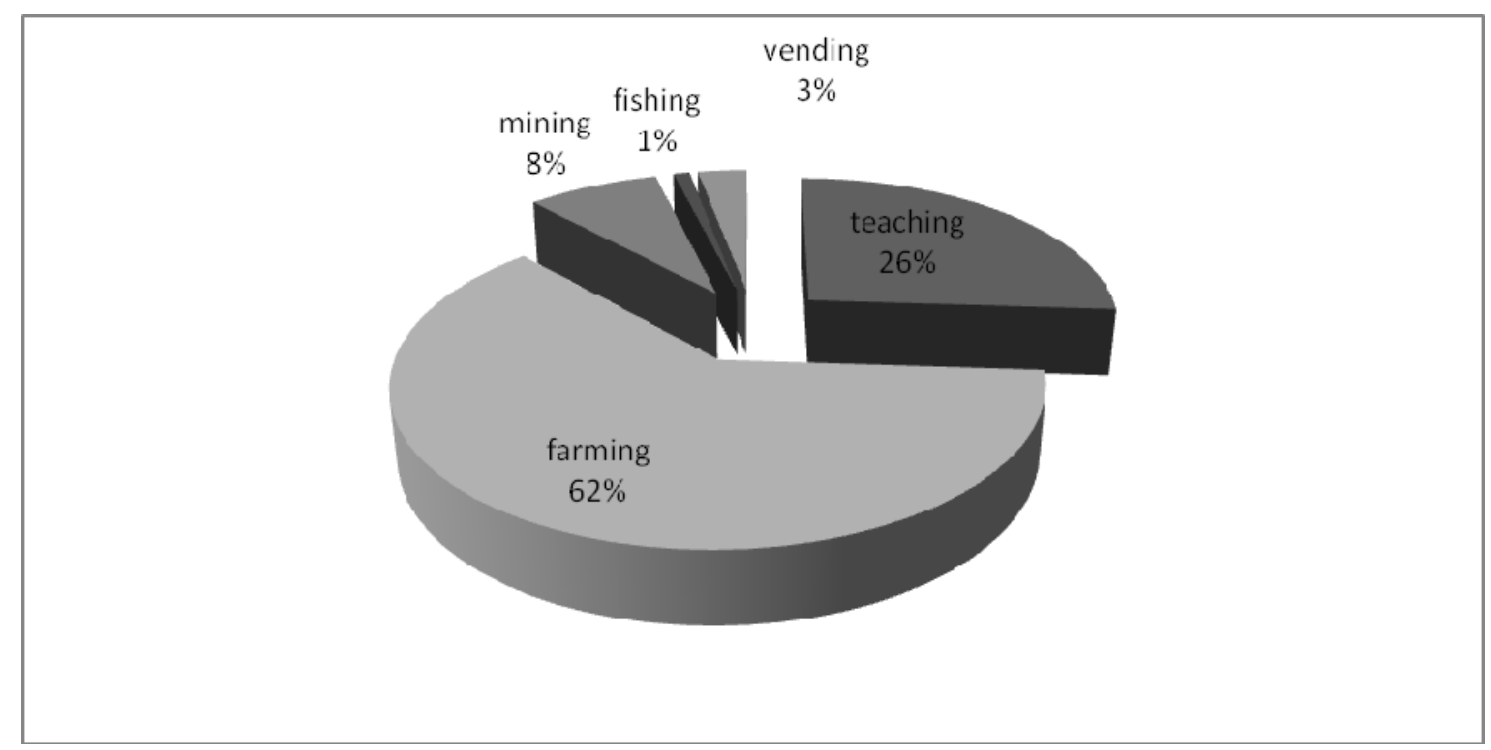

Figure 2. Means of livelihood

Figure 2 shows the distribution of the participants according to their means of livelihood.

The salient feature about Figure 2 is that $62 \%$ of the respondents derive their livelihood from farming which in turn is directly affected by the weather. This implies that they should have a better understanding of indigenous forecasts that they use in their agricultural activities. $26 \%$ are teachers who are better placed to interpret the environmental weather forecasting indicators. 


\subsection{Accessibility of Meteorological Weather Forecasts to the Residents of Wards 12 and 13}

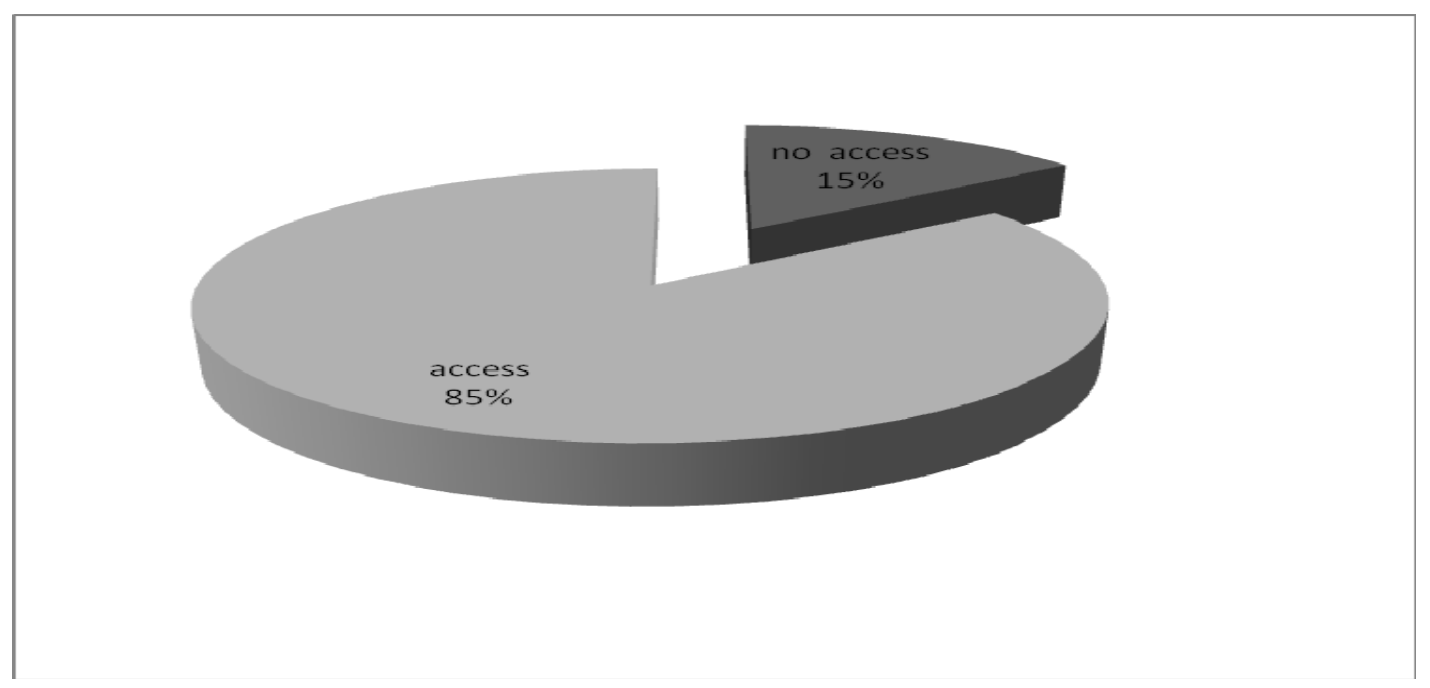

Figure 3. Percentage levels of accessibility of meteorological forecasts by residents.

Figure 3 shows that $85 \%$ of the total sample indicated that they had access to meteorological forecasts and only $15 \%$ said they had no access to these forecasts. This high rate of accessing meteorological forecasts does not translate into adept decision making because of lack of skill in interpretation of the meteorological forecasts. This compels them to rely on their indigenous weather forecasts.

Table 1 shows gender characteristics of the composition of wards 12.and 13. Males and females interviewed for corresponding age groups are shown. Table 2 shows the number of people who have resided in the ward for a given period. For example 3 males have resided in ward 12 for over 80 years and 5 females of the same ward have been residents for $51-60$ years. It can be deduced from table 2 that 31 males and 13 females have resided in both wards for 51 years and above. This could mean that most of the interviewees had good knowledge of the local environment, weather forecasting environmental indicators and their interpretations.

For both wards, 40 respondents have been resident in the area for 51 years and above. This could mean that the information they gave was reliable and authentic. The total sample for the two wards comprised 51 males and 28 females. The composition of the sample indicates that there were more male respondents than females. This could be due to the patriarchal nature of the society where women are not free to interact with strangers.

\subsection{Identification of Indigenous Weather Forecasting Indicators}

\subsubsection{Celestial Bodies Indicators}

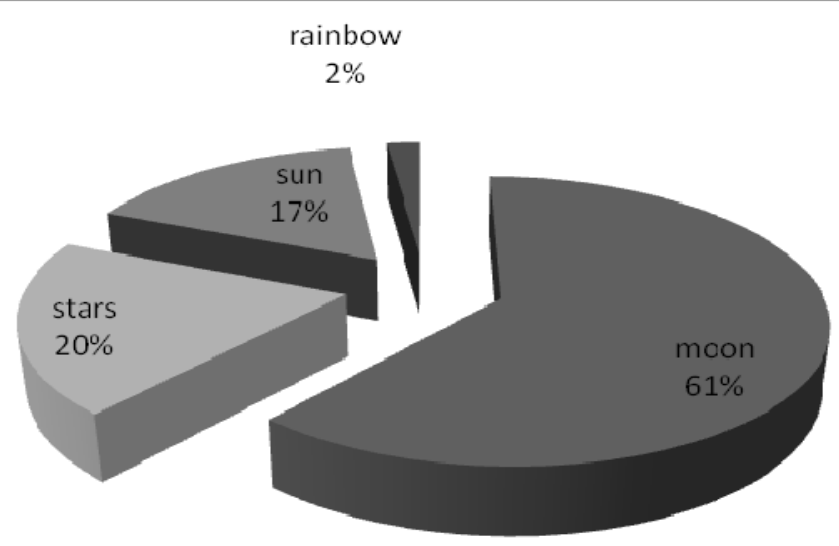

Figure 4. Pie chart showing percentage frequency of the use of celestial indicators 
Figure 4 shows that the most used celestial indicators are the moon (62\%), stars $(26 \%)$, sun $(17 \%)$ and the rainbow $(2 \%)$. The moon, stars and the sun are widely used as indicators to derive seasonal rainfall forecasts.

Table 4. Interpretation table for celestial body indicators

\begin{tabular}{|c|c|c|}
\hline & Behavioral sign & Forecast \\
\hline \multirow[t]{3}{*}{ SUN } & 1.Presence of halo around the sun & Heavy rains are expected \\
\hline & 2 Very hot in October and September & Rains expected soon \\
\hline & 3 The occurrence of an eclipse & $\begin{array}{l}\text { Enhanced chances of a good rainfall } \\
\text { season }\end{array}$ \\
\hline \multirow[t]{6}{*}{ MOON } & 1 A moon with tilted orientation & Drought expected \\
\hline & 2 The moon with normal orientation & Rains expected soon \\
\hline & 3 Full moon (Jenaguru) & Rains unlikely \\
\hline & 4 Halo around the moon & Abundant rains expected \\
\hline & 5 Appearance of $1^{\text {st }}$ quarter and last quarter & Good chances of rain exist \\
\hline & 6 No moon (Mhindo) & Chances of rain falling are enhanced \\
\hline \multirow[t]{6}{*}{ STARS } & 1 Few stars appearing & Rains about to come \\
\hline & $\begin{array}{l}2 \text { Star for good rainfall(Maguta) bigger than star for } \\
\text { drought(manzara) }\end{array}$ & $\begin{array}{l}\text { A good rainfall season expected and } \\
\text { vise versa }\end{array}$ \\
\hline & $\begin{array}{l}3 \text { Drought star (Manzara) appearing with Star for good } \\
\text { rainfall(Maguta) missing }\end{array}$ & Drought is expected and vise versa \\
\hline & 4 Big Drought Star (Manzara) on the eastern side & Drought expected \\
\hline & 5 Big Star for good rainfall(Maguta) on the western side & A good rainfall season expected \\
\hline & 6 Plenty of falling stars & Drought expected \\
\hline
\end{tabular}

3.4.2 Weather Indicators

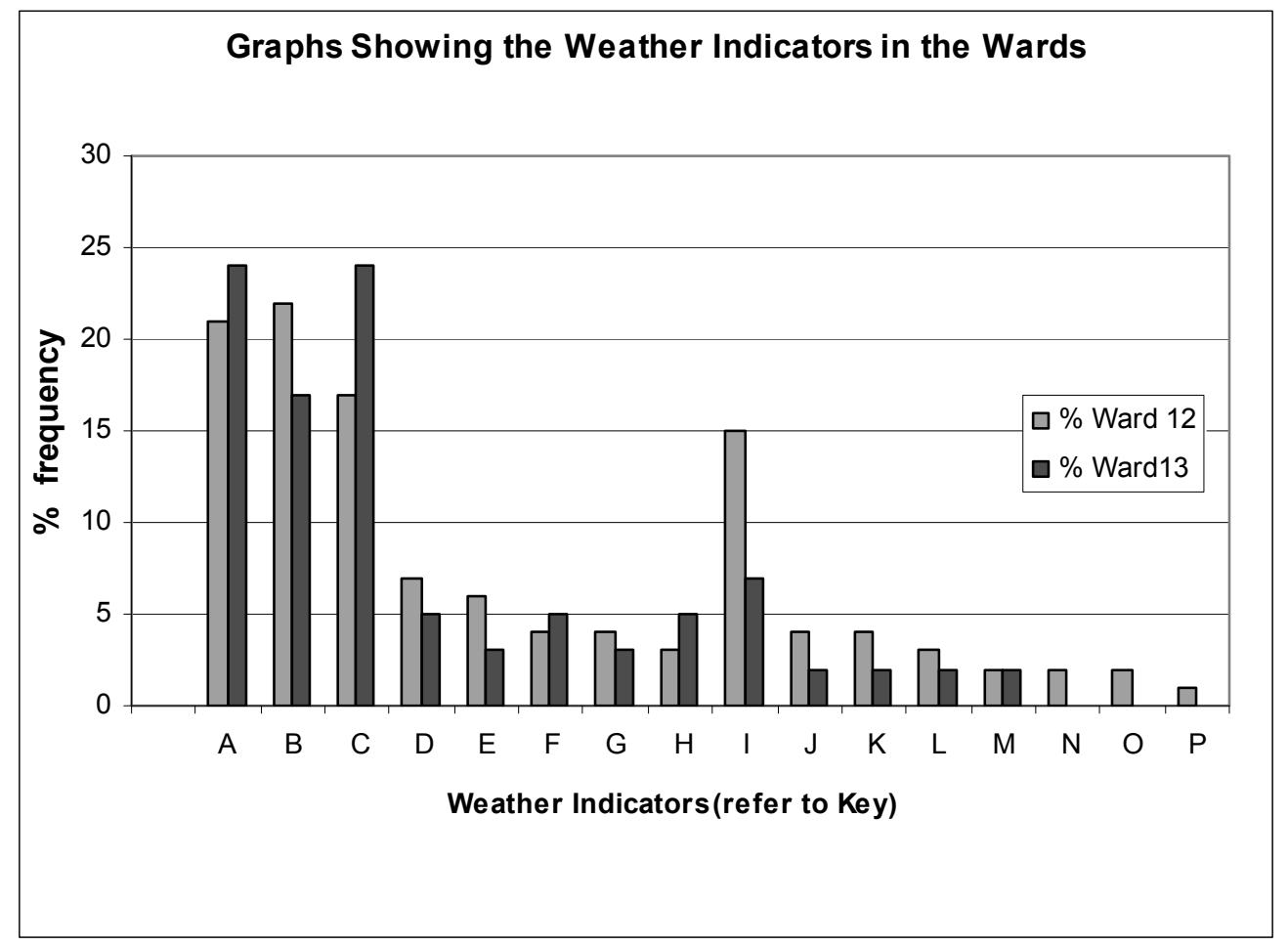

Key 
$\begin{array}{lr}\text { Dew } & \text { A } \\ \text { North-westerly Winds in Summer } & \text { B } \\ \text { Mist } & \text { C } \\ \text { South-easterly winds } & \text { D } \\ \text { Strong Winds } & \text { E } \\ \text { Cold Winter } & \mathrm{F} \\ \text { North-easterly Winds in Summer } & \mathrm{G} \\ \text { Hot Weather } & \mathrm{H} \\ \text { Southerly Winds } & \mathrm{I} \\ \text { Lightning during night in far north in October/November } & \mathrm{J} \\ \text { Whirlwinds } & \mathrm{K} \\ \text { Hot Summer } & \mathrm{L} \\ \text { Haze } & \mathrm{M} \\ \text { Hot winter } & \mathrm{N} \\ \text { Cirrus clouds appearing } & \mathrm{O} \\ \text { Extended winter } & \mathrm{P}\end{array}$

Figure 5. Graphs showing the Weather indicators and frequency of use

Figure 5 shows the weather indicators and their corresponding usage frequency in percentages for the two wards. A key is provided for the indicators.

For ward 12, the most frequently used weather indicators are the north easterly winds in summer (B) ranked 1, occurrence of dew in the morning (A) ranked 2, occurrence of mist(C) ranked 3 and southerly winds (I) ranked 4. Analysis of data for ward 13 revealed the following rankings for the identified indicators: occurrence of dew in the morning (A) ranked 1, occurrence of mist(C) ranked 2, presence of north westerly winds in summer (B) ranked 3 and southerly winds in summer (I) ranked 4. Combined ranking for the two wards was as follows; occurrence of dew in the morning (45\%) ranked 1, occurrence of mist (37\%) ranked 2, presents of north westerly winds $(35 \%)$ ranked 3 ,

Table 5. Interpretation table for weather indicators

\begin{tabular}{|c|c|c|}
\hline & Behavioral sign & Forecast \\
\hline \multirow[t]{9}{*}{ WIND } & 1 Northerly becoming southeasterly & Rains are expected soon \\
\hline & $\begin{array}{l}2 \text { The presence of prevailing southeasterly to } \\
\text { easterly winds }\end{array}$ & Drizzly weather expected soon \\
\hline & 3 The dominance of a westerly wind & $\begin{array}{l}\text { Enhanced chances of a good rainfall } \\
\text { season }\end{array}$ \\
\hline & 4 Northerly to north westerly winds & Rainfall expected in about three days \\
\hline & $\begin{array}{l}5 \text { Very strong winds during a threatening rainfall } \\
\text { event }\end{array}$ & $\begin{array}{l}\text { Jeopardizes the chance of good rainfall } \\
\text { amounts }\end{array}$ \\
\hline & $\begin{array}{l}6 \text { The presence of a prevailing easterly wind for a } \\
\text { long time }\end{array}$ & Drought expected \\
\hline & 7 Dry southerly winds in summer & A dry spell expected \\
\hline & 8 Northerly winds in summer & Rainfall expected within a few days \\
\hline & 9 The prevalence of whirlwinds in August & Signifies early rains \\
\hline \multirow[t]{2}{*}{$\begin{array}{l}\text { WEATHER } \\
\text { CONDITION }\end{array}$} & $\begin{array}{l}1 \text { Hazy weather from September to early } \\
\text { November }\end{array}$ & A good rainfall season expected \\
\hline & 2 Haze in August & Heralds the early onset of the hot season \\
\hline
\end{tabular}


3 Appearance of mist on Mount Mberengwa and Mount Vuzhe

4 The occurrence f mist during the morning Halo around the moon

5 Presence of morning dew

6 Absence of morning dew

7 Very hot weather from September to October

8 Lightning in the far north in October

9 Rainbow appearing just before a rainfall event

10 Very hot and humid conditions in summer

11 Lightning from the west in summer

12 Appearance of cirrus cloud

13 Extended cold winter

14 Warmer than normal winter
Rains expected in one to two days time

A hot afternoon is expected

No rains expected for the next 24 hours

Conditions for convective rainfall are favourable

A good rainfall season expected

Heralds the onset of the rainfall season

Failure of the rainfall event predicted

Signify good chances of thunderstorms

No immediate rains expected

Ideal conditions for precipitation are getting established

Signifies drought to come

Drought expected the coming season

\subsection{Focus Group Discussions}

Two focus group discussions were conducted, one for each of the two wards. Ward 12 group discussion was comprised of 20 people, 13 males and 7 females while ward 13 group discussion comprised 16 people, 10 males and 6 females. Group discussions were important in this study because interpretations of indicators at times differed with respondent. So there was a dire need to synchronize these and come up with a consensus interpretation for each of the abiotic indicators. Where there was disagreement, the interpretation given by the majority was adopted. Clarification of issues where there were differences was necessary and it was achieved through these group discussions.

\subsubsection{Celestial Indicators}

There was consensus on the identification and interpretation of celestial indicators for both wards. The group discussions confirmed the data related to the use of celestial bodies that was collected through questionnaires.

\subsubsection{Weather Indicators}

There was concurrence on both identification and interpretation for most indicators save for the occurrence of dew in the morning where there were divergent views. Some said its occurrence in the morning signifies rain later during the day while others said this was a sign of no rain that day. However, the majority went for its occurrence and absence in the morning as indicating no rains and rains that day respectively.

\subsection{Interviews with Selected Key Persons}

Very few persons were selected because of age restriction and senility. Four and two persons were interviewed in ward 12 and ward 13 respectively. These interviews were carried out after the administration of questionnaires and group discussions.

\subsubsection{Celestial Indicators}

There was consensus on the identification and interpretation of celestial indicators for both wards. However this group of respondents added the rainbow as a weather indicator.

\subsubsection{Weather Indicators}

Respondents were in agreement for both wards for most of the indicators save for dew and mist. Respondents from ward 13 indicated that the occurrence of mist in the morning is a reliable sign of rainfall later that day while those in ward 12 said this was a sign of a bright sunny day that afternoon. The occurrence of dew was interpreted by these elders as also sign of rain within the next few days in both wards.

\subsection{Ranking of Indicator Categories}

Ranking of the indicator categories was done using information from the questionnaires, group discussions and 
interviews with the selected key persons. The ranking was done for each of the two wards from which the combined ranking for the two was derived.

\subsubsection{Ranking of the Indicator Categories from Questionnaires}

Ranking of the indicator categories was done by asking the respondents to rate on a scale 1 to 5 the most used or important indicator categories. The results for the two wards were as follows:

Table 6. Ranking and combined ranking of indicator categories for wards 12 and 13 from questionnaire

\begin{tabular}{llllll}
\hline & Ward 12 & \multicolumn{3}{c}{ Ward13 } \\
\hline Indicator Category & \% Response & Rank & \% Response & Rank & Combined Ranking \\
Weather Indicator & 70 & 1 & 85 & 1 & 1 \\
Celestial Indicator & 30 & 2 & 15 & 2 & 2 \\
\hline
\end{tabular}

From the ranking shown on table 4.5 the following observations can be made:

1) The weather indicator is ranked 1 for both wards.

2) The celestial indicators are ranked 2 for both wards

3) The combined ranking agrees with the ranking of the two wards.

The low response ranking rate for celestial indicators in ward 13 might be attributed to the fact the respondents were mostly young people who were not experienced enough to use celestial indicators.

\subsubsection{Ranking of Indicator Categories from Group Discussions}

Each of the two wards had indicator categories ranked by the respective group discussion; thereafter the combined ranking for the two wards was obtained. It imaged that the majority still ranked weather indicators as 1 and celestial indicators as 2

\subsubsection{Ranking of Indicator Categories from Interviews with Selected Key Person}

Six persons were interviewed as follows, 4 from ward 12 and 2 from ward 13. These elders were asked to rank the order of importance of the indicator categories in their local language

Table 7. Ranking and combined ranking of indicator categories for wards 12 and 13 from the selected key persons

\begin{tabular}{llll}
\hline & Ward 12 & Ward13 & Combined Ranking \\
Indicator Category & Rank & Rank & \\
\hline Weather Indicator & 1 & 1 & 1 \\
Celestial Indicator & 2 & 2 & 2 \\
\hline
\end{tabular}

The interesting and most important observation from these elders was that there was consensus in the ranking order for both wards. These are the same ranking categories obtained from questionnaires and group discussions. A key point that emerged was that all the key persons could in one way or another use the celestial weather indicator which was not the case with the group discussions and questionnaire respondents.

\section{Conclusion}

In the light of the findings above it can be concluded that the people of Mberengwa wards 12 and 13 rely heavily on abiotic and biotic weather forecasting systems as opposed to using meteorological forecasts. The findings from this study confirm findings by Makwara (2013), Rusiro et al (2012) Shoko \& Shoko (2011). It can also be concluded that there is need to utilise the indigenous weather forecasting systems to augment the conventional weather forecasts from the Meteorological department. Local residents in most cases do not understand the meteorological forecasts, so immense benefits can be realised if this type of forecasting system, which is better, understood by the majority of the residents is improved. 


\section{Recommendations}

In view of this, the following recommendations are made:

1) Synchronisation of the Indigenous weather systems (Iws) and the conventional meteorological forecasts to come up with a product that is a hybrid of the two forecasting systems is essential.

2) The indigenous people should be given some education on what a weather forecast is, the terminology used for its dissemination, its benefits and its limitations.

3) There is need for documentation of the a biotic indicators, clearly indicating how they are used so that they could be readily accessible to everyone.

4) Communities could assign or employ someone to assess and gather information on abiotic weather forecasting indicators prior to the onset of the rainfall season. This information could be used to produce a seasonal forecast.

5) There is need to teach people how the Iks and Meteorological forecasts can be used for planning purposes. For example choice of a crop to grow that season and irrigation scheduling. This should be done for both seasonal and short period forecasts, such as the daily weather forecasts.

\section{References}

Central Statistics Office. (1992). Midlands Province Population Census. Harare, Zimbabwe: CSO.

FAO. (1997). Agriculture, Food and Nutrition for Africa. FAO Publishing Management Group. Rome.

FAO. (1998). Indigenous knowledge for watershed management in the UpperNorth-West. Retrieved from http://www.fao.org/docrep/X5672e09.htm

Makwara, E. C. (2013). Indigenous knowledge systems and modern weather forecasting: Exploring the linkages. Journal of Agriculture and Sustainability, 2(1), 98-141.

Mararike, C. (1999). Survival strategies in rural Zimbabwe: The role of assets, indigenous knowledge, and organisations. Mond Books. Harare. Zimbabwe.

Ministry of Foreign Affairs Zimbabwe. (2011). Zimbabwe in brief - agriculture. Retrieved from http://www.zimfa.gov.zw/index.php?option=com

Nyong, A., Adesin, F., \& Elasha, O.B. (2007). The value of indigenous knowledge in climate change mitigation and adaptation strategies in the African Sahel, Climate Change Adaptation in Africa Programme. Mitig Adapt Strat Glob Change, 12, 787-797. http://dx.doi.org/10.1007/s11027-007-9099-0

Risiro, J. D., Mashoko, D., Tshuma, T., \& Rurinda, E. (2012). Weather forecasting and indigenous knowledge systems in Chimanimani district of Manicaland, Zimbabwe. Journal of Emerging Trends in Educational Research and Policy Studies, 3(4), 561-566.

Shoko, K. (2012). Indigenous weather forecasting systems: A case study of the biotic weather forecasting indicators for wards 12 and 13 in Mberengwa district Zimbabwe. Journal of Sustainable Development, 14(2).

Shoko. K., \& Shoko, N. (2011). A comparative analysis of perception levels of accuracy for indigenous weather forecasts and meteorological forecasts: The case of wards 13 and 13, Mberengwa district, Zimbabwe. The Dyke, 5(1).

UNEP. (2002). Africa environment outlook, past present and future perspectives. Earthprint Ltd, UK.

Zimbabwe Met Department. (1981). Climate hand book of Zimbabwe. Government Printers. Retrieved January 13, 2012, from http://www.telegraph.co.uk/earth/earthnews/3301595/Australia-taps-Aboriginal-weather-knowledge.html 